\title{
The clinical application of brain computerized tomography in psychiatry
}

\author{
Mohsen Maroufi*1, Faranak Kianvash ${ }^{2}$ and Hossein Giahchin ${ }^{1}$
}

Address: ${ }^{1}$ Isfahan University of Medical Sciences, Behavioral Science Research Center, Iran and ${ }^{2}$ Oil Company Health Service

* Corresponding author

from International Society on Brain and Behaviour: 2nd International Congress on Brain and Behaviour

Thessaloniki, Greece. 17-20 November 2005

Published: 28 February 2006

Annals of General Psychiatry 2006, 5(Suppl I):SI86 doi:I0.1I86/I744-859X-5-SI-SI 86

\section{Background}

The diagnosis of psychiatric disorders is mainly made on the base of clinical interview and physical/mental examination of the patient. The clinical application of laboratory tests is limited to rejection of probable medical causes which may lead to emerge of mental manifestations. For assessing the efficiency of brain computerized tomography in this respect, a study was conducted.

\section{Materials and methods}

All of the hospitalized patients in psychiatric emergency unit of Isfahan Medical School for six months were examined in the view of demographic characteristics, clinical diagnosis, and the number of performed brain computerized tomography and their results.

\section{Results}

Brain computerized tomography was requested for 142 patients among the 408 hospitalized patients in psychiatric emergency unit. Among the performed scans only in one case ( 0.7 percent), mild brain atrophy was reported and the remaining 141 scans were normal or at limit level of normal.

\section{Discussion}

According to limited diagnostic value of brain computerized tomography in psychiatry and also techno-economic problems, the accurate assessment of its actual application, especially in our society, seems necessary.

\section{References}

I. Rao R: Cerebrovascular disease and late life depression. Int J Geriatic Psychiatr 2000, 15:419-433.

2. Gross R, Goshen E: Brain imaging and its clinical application in psychiatry. Harefuah 1997, 133:337-342.
3. Moles JK, Franchina JJ: Increasing the clinical yield of computerized tomography for psychiatric patients. Gen Hosp Psychiatry 1998, 20:282-291.

4. Sadvall G: Image processing in psychiatry. Fortschr Neurol Psychiatr 1994, 62:39-43. 